\title{
25 Research Square \\ Development the Clinical Guideline of Human Milk Bank in Iran
}

\section{Arezoo Yousefi}

Islamic Azad University of Khorasgan Nursing and Midwifery Faculty https://orcid.org/0000-00026211-7656

Narges Sadeghi ( $\sim$ n45sadeghi@yahoo.com )

Islamic Azad University https://orcid.org/0000-0003-3580-0326

\section{Soheila Jafari-mianaei}

Isfahan University of Medical Sciences and Health Services School of Nursing and Midwifery

\section{Research}

Keywords: Clinical guideline, MMB, infant, Iran

Posted Date: May 6th, 2021

DOl: https://doi.org/10.21203/rs.3.rs-336307/v1

License: (c) (i) This work is licensed under a Creative Commons Attribution 4.0 International License. Read Full License 


\section{Abstract \\ Background}

Clinical guidelines are recommendations produced by systematic methods assisting health care providers in making the right decisions. The existence of Mothers' Milk Banks (MMBs) plays an important role in increasing exclusive breastfeeding in low birth-weight infants. More than one million infants under one year of age die annually because they are not breastfed. The present study was done to develop a clinical guideline for MMB.

\section{Methods}

The study was a multistage integrated study conducted in three steps according to the NICE model. In the first step, the components of a clinical guideline for MMB were determined through multiple data centers to search and resource integration and a draft was subsequently prepared. In the second step, each component was reviewed considering the expert agreement and the clinical guideline was finally developed. In the third step, the AGREE questionnaire was used by 10 experts to measure the utility and quality of the proposed program as well as its national feasibility. Quantitative data was analyzed in SPSS20 using descriptive statistics.

\section{Results}

The clinical guideline included the necessary measures before MMB development (establishing MMB infrastructure, enhancing awareness for supporting MMB, creating a network for communicating with different units, developing the key rules and guidelines as well as ethical points) and the necessary measures while using MMB (donors, working processes on the donated milk, and the recipients). The content was reviewed by forming a focus group and their corrective comments were considered in the clinical guideline. Utilizing the AGREE tool, the results of the survey showed that $90 \%$ of the respondents strongly recommended guideline use.

\section{Conclusions}

It is hoped that this clinical guideline, provided by the order of Neonatal Health Bureau based on the culture and religion of the Iranian community, could be an effective step to improve the care and treatment process of preterm infants. Moreover, with the proper use of it, the treatment team staff can support the premature infants and their parents by promoting breastfeeding and reducing the side effects of using formula and the mortality of this group of infants.

\section{Background:}


Since many years ago, the proper nutrition of infants has been considered as the most important global concerns to deal which using breast milk has been the most natural and the best way. Nutrition from $\mathrm{MMB}$ is a new approach to reach this goal whose theory has been raised in America and Europe in the twentieth century [1]. Breast milk is the best choice for feeding an infant [2]. There are more than 400 useful substances like white blood cells and immunoglobulin in breast milk, not able to be obtained in laboratories, which protect the infant from the disease [3]. The short duration of breastfeeding, especially in developing countries, has been a serious problem. Annually, more than one million children under 12 months of age die due to the non-use of breast milk. Unfortunately, only $36 \%$ of infants around the world are exclusively fed from breast milk. It occurs when the donated milk is the best substitution for the infants whose mothers are unable to provide an adequate supply of milk [4]. In spite of the superiority of breast milk over formula, this method is rarely used now [5]. One of the main reasons for ignoring pasteurized breast milk is an increase in the production of formula. Artificial feeding-related complications are very high in the sick, premature, and weak neonates and in those whose mothers are unable to breastfeed [6]. In the absence of the infants' required breast milk, another mother's milk may be used, especially for very low birth-weight infants. International organizations like UNICEF and the World Health Organization (WHO) advocate the establishment of MMB as an effort to promote and support breastfeeding programs. MMBs are a significant source for supplying milk in many neonatal intensive care units (NICUs) in developing countries [7]. The existence of MMB in NICUs plays an important role in increasing exclusive breastfeeding particularly in low-birth-weight infants and an objective need of guidelines is therefore felt in all countries to establish and commissioning MMBs [6]. MMB is a place for collecting, pasteurizing, storing, and distributing the donated milk and is recommended if the breast milk is not available or adequate [8]. Factors such as the employed mothers, others' advice and, most importantly, the mothers' false beliefs and their attitudes toward breastfeeding reduce or stop breastfeeding [9]. Longer periods of breastfeeding are closely associated with mother's higher selfconfidence in the period of breastfeeding, less anxiety and depression, higher self-esteem, and healthier social relationships [10].

MMBs are centers that collect, pasteurize, and store milk expressed by volunteer mothers, and then feed babies who are deprived of breast milk for any reason [11]. MMB is a financially unprofitable institution operating to supply pasteurized milk during the process of donating milk as well as screening, storing, and distributing donated milk according to the existing protocol [12]. MMB was firstly founded in Boston and subsequently in various European and Asian countries [13]. The first milk bank in Asia, called Sneha, was founded by Amanda Fernandez and started to work in Mumbai. Currently, the growth in the number of these banks compared to that of NICUs is very slow [6].

Matching the clinical guideline to the community culture is a very important point that should not be ignored [14]. The best reason for using these guidelines in health centers is to improve service quality, reduce costs, elevate community health level, and align national standards with international standards [15]. The medical organization considers the eight criteria of clarity of text, transparency of used documents and methods, multi-professional editing, updating, the validity of recommendations, usability, flexibility, being devoid of bias, reliability, and retrieval essential for clinical guidelines [16]. One of the 
applied strategies for operating the plan of the existence of MMB along NICUs in Iran was to design a clinical guideline. Reducing costs, elevating the level of community health and aligning national standards with international standards are of the other reasons justify the usage of clinical guidelines [17]. Developing a clinical practice guideline is a strategy used after establishing an interdisciplinary group, identifying clinical questions, interventions, exposures, and outcomes [18].

With the investigations done among the papers related to MMBs in Iran, one of the existing problems in Iran seems to be the lack of national clinical guidelines. Moreover, MMB is an emerging concept that has recently become one of the priorities of the Ministry of Health. Thus, the researchers have tried to address this issue according to the policies of the Neonatal Health Department. Utilizing the existing standards in the papers, books, and international clinical guidelines of MMB as well as the experts' views with the aim of localizing other countries' clinical guidelines, the researchers have developed a clinical guideline to establish and make use of MMB. This way, they hope to take a step to provide the children of this country with service.

\section{Methods:}

The present study was a multi-stage integrated study designed and developed using the guidelines of other countries and the viewpoints of the expert group in accordance with Iranian culture and religion. The clinical guideline for MMB was prepared with the modeling of the NICE model and other databases that are closer to the research subject [19]. The study was conducted in three steps:

\section{The First Step: Advanced Text Review}

The first stage of the study was done to determine the contents of MMB clinical guidelines. The inclusion criteria were valid sites and the papers published from 2000 to 2018. Priority was given to the papers written in the field of the clinical guideline of MMB or the ones developed through a systematic review or meta-analysis. The Papers whose full text was not available or were unrelated to the subject were excluded.

The research environment was all global sites, libraries, and electronic resources. The population under study was papers, clinical guidelines, and related scientific books to the subject obtained through advanced searches of texts. To access to the global clinical guidelines and papers on MMBs, the relevant keywords based on (Table 1) were used to probe. The papers that met the inclusion criteria were selected using non-probability and convenience sampling methods. These papers constituted the sample size. Finally, 1235 papers and guidelines were included in the study. In this step, the draft of the clinical guideline was prepared.

Table 1: Combination of keywords in systematic research 


\begin{tabular}{|c|c|c|c|}
\hline \multicolumn{4}{|c|}{ Key Word and Combination } \\
\hline Milk banking & Mother milk bank & AND & Guideline \\
\hline Mother milk banking & Breast milk bank & & Protocol \\
\hline Human milk banking & $\begin{array}{l}\text { Human milk bank } \\
\text { Donor milk bank }\end{array}$ & & Pathway \\
\hline
\end{tabular}

The Second step: Determining the Expert Group Agreement

The second stage was designed for determining the degree of agreement of the expert group on the components and the content of the clinical guideline draft. The prepared draft was sent to 30 specialists (according to the Neonatal Health Department) across the country. Their corrective comments were then applied according to (Table 2) in the above guideline.

When a care guideline is prepared, this guideline should be reviewed by representatives from different disciplines. The viewpoints of knowledgeable people should also be taken into account for developing the guideline because they may identify issues not mentioned in the text review and need evaluation [19].

Table 2: Discussed items in the focus group 


\begin{tabular}{|c|c|c|c|}
\hline & $\begin{array}{l}\text { The specified items for } \\
\text { discussion in the focus } \\
\text { group }\end{array}$ & $\begin{array}{c}\text { The focus group's Comments and } \\
\text { suggestions on the item (the reasons for } \\
\text { discussion) }\end{array}$ & $\begin{array}{l}\text { The discussion result (rejection } \\
\text { or acceptance of the } \\
\text { discussion) }\end{array}$ \\
\hline 1 & $\begin{array}{l}\text { The clinical guideline of } \\
\text { mother milk bank }\end{array}$ & $\begin{array}{c}\text { Change to the clinical guideline of } \\
\text { mothers' milk bank }\end{array}$ & Rejection \\
\hline 2 & Treating the donated milk & Preparing the donated milk & Acceptance \\
\hline 3 & $\begin{array}{l}\text { Help the high-risk infants } \\
\text { requiring breast milk to } \\
\text { live longer }\end{array}$ & $\begin{array}{l}\text { Improve the high-risk infant health and } \\
\text { improve their early prognosis }\end{array}$ & Acceptance \\
\hline 4 & $\begin{array}{c}\text { Guideline realm (in } \\
\text { Neonatal Intensive Care } \\
\text { Units (NICU)) }\end{array}$ & $\begin{array}{c}\text { Clinical guideline real ( in hospitals and } \\
\text { healthcare centers having Neonatal } \\
\text { center and NICU) }\end{array}$ & Acceptance \\
\hline 5 & $\begin{array}{l}\text { Clinical guideline users } \\
\text { (top managers) }\end{array}$ & $\begin{array}{l}\text { Clinical guideline users (head and } \\
\text { managers of hospital) }\end{array}$ & Acceptance \\
\hline 6 & $\begin{array}{l}\text { Clinical guideline users } \\
\text { (pediatricians, sub- } \\
\text { specialist of neonates) }\end{array}$ & $\begin{array}{l}\text { Clinical guideline users (pediatricians, } \\
\text { sub-specialist of neonates, gynecologists, } \\
\text { nutritionists, clinical biochemistry }\end{array}$ & Acceptance \\
\hline 7 & $\begin{array}{l}\text { Clinical staff and } \\
\text { healthcare team }\end{array}$ & $\begin{array}{c}\text { Nursing and assistance personnel, } \\
\text { laboratory experts, other staff working In } \\
\text { the hospital }\end{array}$ & $\begin{array}{l}\text { Acceptance (nurses of the } \\
\text { neonatal unit, midwife, and } \\
\text { other staff at the health } \\
\text { centers }\end{array}$ \\
\hline 8 & $\begin{array}{l}\text { Supportive staffs of breast } \\
\text { milk donors }\end{array}$ & $\begin{array}{l}\text { Other administrative and service } \\
\text { personnel attracting breast milk donors }\end{array}$ & Rejection \\
\hline 9 & $\begin{array}{l}\text { Community health } \\
\text { practitioner (family } \\
\text { physician) }\end{array}$ & General practitioner (family physician) & Acceptance \\
\hline 10 & Treating the donated milk & $\begin{array}{l}\text { Transferring and preparing the donated } \\
\text { milk }\end{array}$ & $\begin{array}{c}\text { Acceptance (preparing the } \\
\text { donated milk) }\end{array}$ \\
\hline 11 & $\begin{array}{l}\text { The religion issue specific } \\
\text { to our country }\end{array}$ & Executive priority & Acceptance \\
\hline 12 & The issue of religion & $\begin{array}{l}\text { Low priority and feasibility due to } \\
\text { contradiction with different religions }\end{array}$ & $\begin{array}{l}\text { Acceptance provided that the } \\
\text { religion issue will be clarified }\end{array}$ \\
\hline 13 & The lactation consultant & Lactation consultant in mother milk clinic & Acceptance \\
\hline 14 & Pasteurizing the preserver & Pasteurizing the holder & Acceptance \\
\hline
\end{tabular}

Page 6/15 


\begin{tabular}{|c|c|c|c|}
\hline 15 & Quick freezing of the milk & Quick cooling of the milk & Acceptance \\
\hline 16 & Pumping the breast milk & Breast pump & Acceptance \\
\hline 17 & $\begin{array}{c}\text { Is it necessary to mention } \\
\text { to the demerits of using an } \\
\text { electric breast pump }\end{array}$ & Low priority (is it necessary?) & $\begin{array}{l}\text { Acceptance (it is better to be } \\
\text { mentioned) }\end{array}$ \\
\hline 18 & $\begin{array}{l}\text { Estimating the cost of } \\
\text { setting up the milk bank }\end{array}$ & Low priority & Rejection \\
\hline 19 & $\begin{array}{l}\text { Alcohol drinking of the } \\
\text { donor }\end{array}$ & Low priority (no alcohol drinking) & Rejection \\
\hline 20 & Visiting the donor home & It is possible? & Acceptance \\
\hline
\end{tabular}

In this step, the research environment included the universities of Medical Sciences in Isfahan, Tabriz, Mashhad, Shiraz and the Neonatal Health Department in the Ministry of Health and Medical Education. The population under study was the faculty members of the above institutions and universities. The inclusion criterion was having expertise in the field of breast milk tailored to the content of clinical guidelines (sub-specialist of neonates, a specialist in religious affairs of breast milk, nurses with bachelor and master degrees). The exclusion criterion was the reluctance to cooperate in the study. As the researchers were looking for the people whose specialist knowledge was breast milk, the sampling was therefore purposive at this stage. Those specialists who were participating in this stage formed the sample size. Since the clinical guideline was sent to 30 people and only 25 people submitted their corrective comments, the final sample size included 25 people.

\section{The Third Step: Determining the Quality and Utility of the MMB Guideline}

The third stage was done to determine the quality and utility of the prepared guideline. The AGREE questionnaire was used to reach the above goal. The AGREE tool is a generic tool that is designed to provide a framework for evaluating the quality of clinical guidelines, whereby one can assess the clinical guideline. The quality of clinical guidelines indicates that every possible bias is avoided in the process of developing guidelines, the internal and external validity of the recommendations is provided, and the recommendations can be implemented in the clinic. This means considering the advantages, disadvantages, costs of the recommendation as well as the practical aspects of implementing recommendations. The AGREE tool evaluates the quality of content presentation and some aspects of recommendations and examines the success likelihood of the clinical guideline in reaching the desired behavioral consequences (predictive validity of the guideline) [20]. In this stage, the research environment was Isfahan University of Medical Sciences, Isfahan Islamic Azad University (Khorasgan), and Amin and Alzahra hospitals. The research population was the employed faculty members and nurses in the above hospitals. The inclusion criterion was having expertise regarding the breast milk and the exclusion criterion was the reluctance to cooperate in the study. The researchers were looking for people with expertise in breast milk, so the sampling at 
this stage was purposive. The number of participants at this stage constituted the sample size. As the clinical guideline was sent to 20 people and just 10 returned their corrective comments, the sample size was equal to 10 . The results were then analyzed by SPSS20 utilizing descriptive statistics.

\section{Results:}

\section{The Results of the First Step}

At this step, different components of MMB and the related clinical guideline were identified and extracted by means of databases. After searching, 1235 papers and clinical guidelines were found (Flowchart 1). The available papers were reviewed and 29 articles and clinical guidelines were subsequently selected. After studying and translating the papers and the clinical guidelines, the recommendations were extracted whose scientific validity was confirmed with the help of the supervisor and the advisor and the main components of MMB were accordingly determined for developing the clinical guideline. After extracting the information about MMBs around the world, the clinical guideline was divided into two main parts; namely, the necessary measures before the development of $M M B$ and the necessary measures while using MMB. This division was done using the guideline of strengthening MMB in England [21]. The data analysis at this stage led to the preparation of the clinical guideline sections of MMB and the initial draft.

\section{Results of the Second Step}

At this stage, the draft of the clinical guideline was emailed to the members of the expert group and the components and contents of the clinical guideline were polled. According to the expert group, only 18 cases of the clinical guideline were discussion-worthy. Of these 20 discussion-worthy cases in (Table 2), 12 cases were accepted, 4 were eliminated, and 4 needed different centralized group, which was modified after consultation with the relevant experts. The applied suggestions and amendments by the expert team led to the final clinical guideline.

\section{The Results of the Third Step}

the quality and utility of the clinical guideline were evaluated at this stage through a survey using the AGREE questionnaire and the results were then analyzed by means of SPSS20 software and AGREE calculation formula with descriptive statistics. The majority of participants at this stage $(70 \%)$ had a Ph.D. and higher. The age range was mostly $40-50$ (80\%). The most prevalent work experience was 1520 years ( $40 \%$ ) and $60 \%$ of the respondents were females and $40 \%$ were males. Moreover, $80 \%$ were married and $20 \%$ were single. The results of the clinical evaluation of quality are presented in (Table 3 ). In the final evaluation, $90 \%$ of the respondents strongly recommended the use of this guideline and $10 \%$ limited its use to some modification which should be made in some recommendations. 
Table 3

Calculation of the final evaluation

\begin{tabular}{|lllll|}
\hline Range & Range items & Frequency & $\begin{array}{l}\text { Range } \\
\text { percentage }\end{array}$ \\
\hline $\begin{array}{l}\text { Final } \\
\text { evaluation }\end{array}$ & $\begin{array}{l}\text { Do you recommend using } \\
\text { this guideline? }\end{array}$ & I strongly recommend & 9 & $90 \%$ \\
\cline { 2 - 4 } & & $\begin{array}{l}\text { I recommend with some } \\
\text { modifications }\end{array}$ & 1 & $10 \%$ \\
\hline & I do not recommend & 0 & 0 \\
\hline & I am not sure & 0 & 0 \\
\hline
\end{tabular}

\section{Discussion:}

In the present study, to develop a clinical guideline for breastfeeding, three steps were taken; namely, the advanced review of the texts, the determination of the expert group agreement, and the determination of MMB guideline quality and desirability using the AGREE questionnaire. The clinical guideline for neonatal palliative care provided by Zargham et al. is also one of the comprehensive guidelines covering an appropriate wide range of neonatal palliative care. Three approaches of reviewing the texts, a centralized and well-known group of specialists, and the AGREE tool were separately used by the researchers in this study [22]. The present study is similar to the above study regarding the method of developing clinical guideline.

There are some components in the provided clinical guideline which correspond to the British MMB Guideline [21]. This guideline had been localized by the expert group considering Iranian culture and religion. Roly et al. also developed the nursing guidelines for the patients under the intervention of aggressive heart attack. In their study, the interventions meant the intense scrutiny of the studies on the care of patients under aggressive cardiac interventions. The scrutiny was conducted based on the evidence-based process where limited access to the studies was a hurdle in this path. In the next step, a team of experts was formed and the care modification was then done according to the Delphi technique [23]. In accordance with the above study, the focus group meeting and Delphi technique were also used in this study.

In a retrospective study, Wileen et al. investigated the valid tools for developing clinical guidelines. The most commonly known tool was AGREE [24]. Tris et al. conducted a study to validate the AGREE tool and to probe the ability of this tool to determine the quality of clinical guidelines. In that study, 100 clinical guidelines from eleven countries had been firstly collected and evaluated separately by 194 evaluators with the use of this tool. The original tool was then modified and three guidelines per country were afterwards selected again and examined by other seventeen evaluators $95 \%$ of whom stated that the AGREE tool was a suitable tool for evaluating the quality and desirability of clinical guidelines [25]. 
In the third stage, the AGREE tool was used to determine the quality and desirability of the clinical guideline. According to more than $60 \%$ of the experts, all parts of this clinical guideline had desirable quality. As Chen et al. mentioned, if most parts of the AGREE tool get a score more than $60 \%$, that clinical guideline will be recommended; if they get score between $30 \%-60 \%$, that will be recommended with undergoing some conditions; and if they get score lower than $30 \%$, that will not be recommended. In the present study, the score of the "feasibility" section of the clinical guideline was lower than that of other sections. In the study by Chen et al., the quality of seven clinical guidelines was measured using the AGREE tool in four of which, the quality of the feasibility section was lower than the rest sections of the study. Considering this, the present study is in line with the study above [26].

\section{Conclusions:}

Physicians and nurses need unified instruction to support infants and their parents in cases where breast milk is not enough or is prohibited. The present clinical guideline includes the guidelines for the construction of MMB in the hospitals including NICU, the process of collecting milk from the donor mothers, pasteurizing, storing and distributing the donated milk in the milk bank.

This guideline was developed in two sections. They were the necessary measures before the development of MMB (stablishing the milk bank infrastructure, enhancing the awareness level for supporting the milk bank, creating a network whereby communicating with different units, expanding the key rules and guidelines and ethical points as well) and the necessary measures while using MMB (donors, working processes on the donated milk, and the recipients) (Cart 1,2). It is hoped that this clinical guideline, which is prepared based on the culture and religion of the Iranian community, could be an effective step to promote the process of care and treatment of premature infants and that with the appropriate use of it, the treatment team staff can protect parents and infants while supporting the promotion of breastfeeding and the reduction of formula side effects and mortality of this group of infants.

\section{Abbreviations}

MMBs

Mothers' Milk Banks

NICE

National Inatitue for Health and Clinical Excellence

\section{Declarations}

Ethics approval: the ethics codes IR.IAU.KHUISF.REC.1397.14

consent to participate: Not applicable

Consent for publication: Not applicable 
Availability of data and materials: The datasets used and/or analysed during the current study are available from the corresponding author on reasonable request.

Competing interests: The authors declare that they have no competing interests.

Funding: Not applicable.

Authors' contributions:

AY substantial contributions to the conception, the acquisition, analysis, interpretation of data, have drafted the work, have approved the submitted version

NS design of the work, the interpretation of data, have substantively revised the work, have approved the submitted version

SJ-M design of the work, the interpretation of data, have approved the submitted version

Acknowledgements

The above paper was extracted from the Master's Thesis of Nursing approved by the Islamic Azad University of Isfahan (Khorasgan) that had been requested by the Neonatal Health Department of the Ministry of Health and Medical Education. Hereby, the researchers express their gratitude to the head of Islamic Azad University of Isfahan (Khorasgan), the Neonatal Health Department, the authorities and staff of the relevant hospitals, and all the participants in the study.

\section{References}

1. NETTING, M. J., CAMPBELL, D. E., KOPLIN, J. J., BECK, K. M., MCWILLIAM, V., DHARMAGE, S. C., TANG, M. L., PONSONBY, A.-L., PRESCOTT, S. L. \& VALE, S. 2017. An Australian consensus on infant feeding guidelines to prevent food allergy: outcomes from the Australian Infant

2. Hockenberry, M.J. and D. Wilson, Wong's Nursing Care of Infants and Children Multimedia Enhanced Version. 2013: Elsevier Health Sciences.

3. TAYLOR, J. 2016. North American Culture: Undermining Breastfeeding.

4. MORROW, A. L. C. J. C. 2013. Breastfeeding Updates for the pediatrician.

5. MIZUNO, K., SAKURAI, M. \& ITABASHI, K. 2015. Necessity of human milk banking in Japan: questionnaire survey of neonatologists. Pediatrics International, 57, 639-644.

6. BHARADVA, K., TIWARI, S., MISHRA, S., MUKHOPADHYAY, K., YADAV, B., AGARWAL, R. \& KUMAR, V. 2014. Human Milk Banking Guidelines.

7. GUO, M. 2014. Human milk biochemistry and infant formula manufacturing technology, Elsevier.

8. Hoodbhoy, S., Human milk banking; current evidence and future challenges. Paediatrics and Child Health, 2013. 23(8): p. 337-341. 
9. Salimi M, Kalantari N. (2011). Factors affecting the duration of breastfeeding. Tehran: National Congress of Maternal and Child Health and Breast Milk. (In Persian)

10. Ravari M, Habibillahi A, Heydarzade M, Rashidi Jazni N, 2017, Breastfeeding Challenges Made Easy forLate Preterm Infants, Neonatal Health Office, MOHME Children Health Office, MOHME Iranian Society of Neonatology. (In Persian)

11. Falahtafti F, 2017, Comparative study of the decision to establish a milk bank in Islamic religions, Jurisprudential research,12, p.111-136. (In Persian)

12. Guidelines HMBANA 2015.pdf>.

13. MORTAZI, A. 2016. Research on the history and necessity of establishing breast milk banks, and related jurisprudential and legal challenges.

14. Heyadri M, Anoshe M, Azadarmaki T, Mohammadi E, 2011, Explaining Nurses' Experiences in Cultural Care of Patient Patients. Iranian Journal of Ethics and Medical History. 4(6). P. 75-86. (In Persian)

15. Mohamadpor A. Comparative standards of hospital hygiene standards of the International Joint Commission on Hospital Accreditation [dissertation]. Tehran: Iran Med Sci Univ 2009.(text in persian)

16. NICE- Donor milk banks service operation 2010.pdf>.

17. AZIZI, M., SIRATI NAYER, M., MOKHTARI NOURI, J. \& MOTAHEDEYAN TABRIZI, E. 2013. Designing and accrediting the evidence-based care guidelines on insomnia and constipation in psychiatric patients. Evidence Based Care, 3, 81-89.

18. BRESSLER, B., MARSHALL, J. K., BERNSTEIN, C. N., BITTON, A., JONES, J., LEONTIADIS, G. I., PANACCIONE, R., STEINHART, A. H., TSE, F. \& FEAGAN, B. 2015. Clinical practice guidelines for the medical management of nonhospitalized ulcerative colitis: the Toronto consensus. Gastroenterology, 148, 1035-1058. e3.

19. Hewitt-Taylor, J., Clinical guidelines and care protocols. Intensive and Critical Care Nursing, 2004. 20(1): p. 45-52.

20. RASHIDIAN, A. \& YOUSEFI-NOORAIE, R. 2012. Development of a Farsi translation of the AGREE instrument, and the effects of group discussion on improving the reliability of the scores. $J$ Eval Clin Pract, 18, 676-81.

21. Strengthening Human Milk Banking 2013.pdf>

22. ZARGHAM-BOROUJENI, A., ZOAFA, A., MAROFI, M. \& BADIEE, Z. 2015. Compilation of the neonatal palliative care clinical guideline in neonatal intensive care unit. Iranian journal of nursing and midwifery research, 20, 309.

23. Rolley JX, Salamonson Y, WensleyC, Dennison CR, Davidson PM. Nursing clinical practice guidelines to improve care for people undergoing percutaneous coronary interventions. Australian Critical Care 2011;24(1):18-38.

24. VLAYEN, J., AERTGEERTS, B., HANNES, K., SERMEUS, W. \& RAMAEKERS, D. 2005. A systematic review of appraisal tools for clinical practice guidelines: multiple similarities and one common deficit. International Journal for Quality in Health Care, 17, 235-242 
25. TERRACE, L. 2003. Development and validation of an international appraisal instrument for assessing the quality of clinical practice guidelines: the AGREE project. Qual Saf Health Care, 12, 1823.

26. Chen K-H, Kao C-C, Liu H-E, Chiu W-T, Kuo KN, Chen CC. Using appraisal of guidelines research and evaluation to appraise nursing clinical practice guidelines in Taiwan and to compare them to international studies. Journal of Experimental \& Clinical Medicine 2012; 4(1):58-61.

\section{Figures}




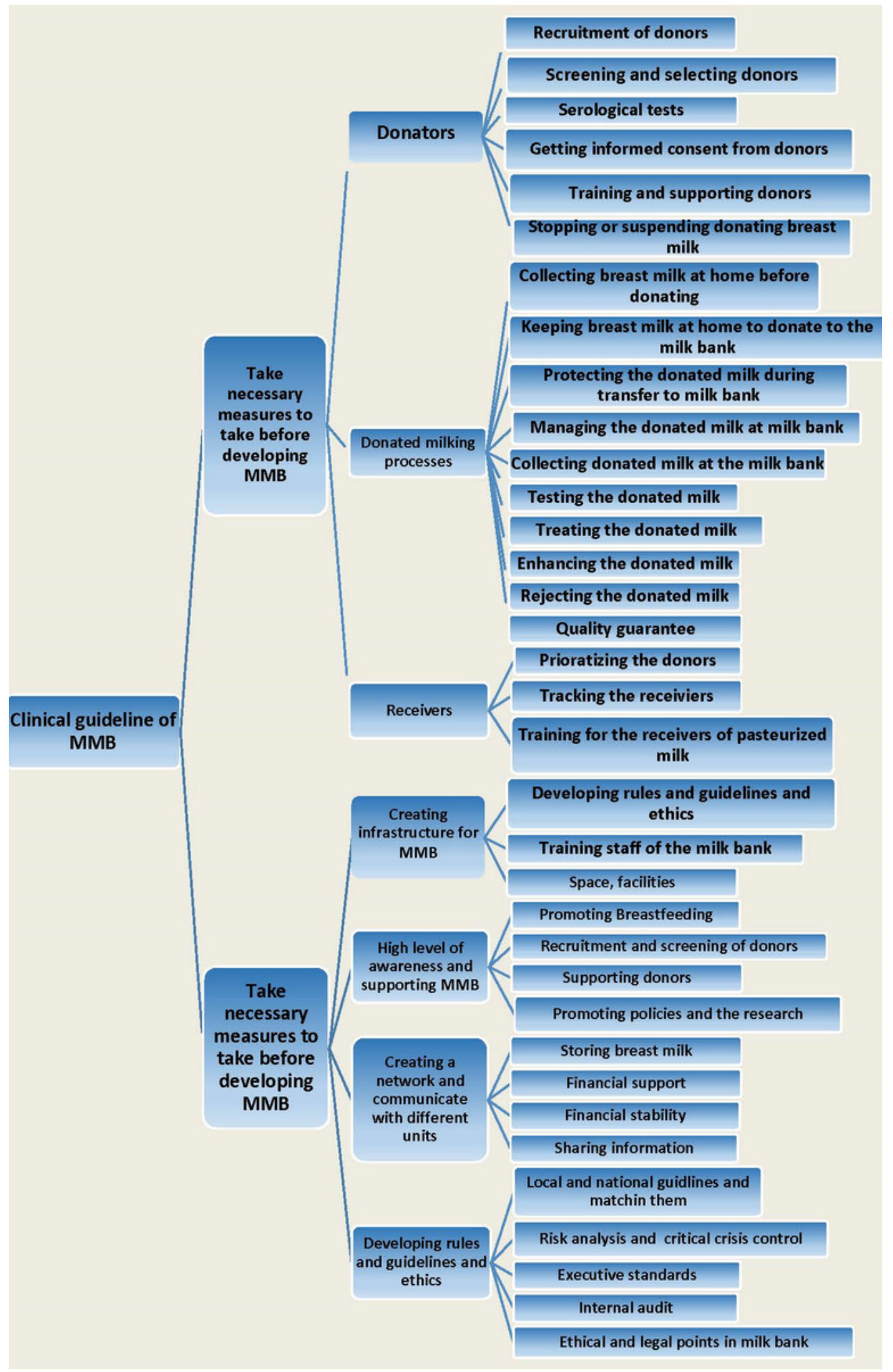

\section{Figure 1}

The clinical guideline of MMB at one glance 


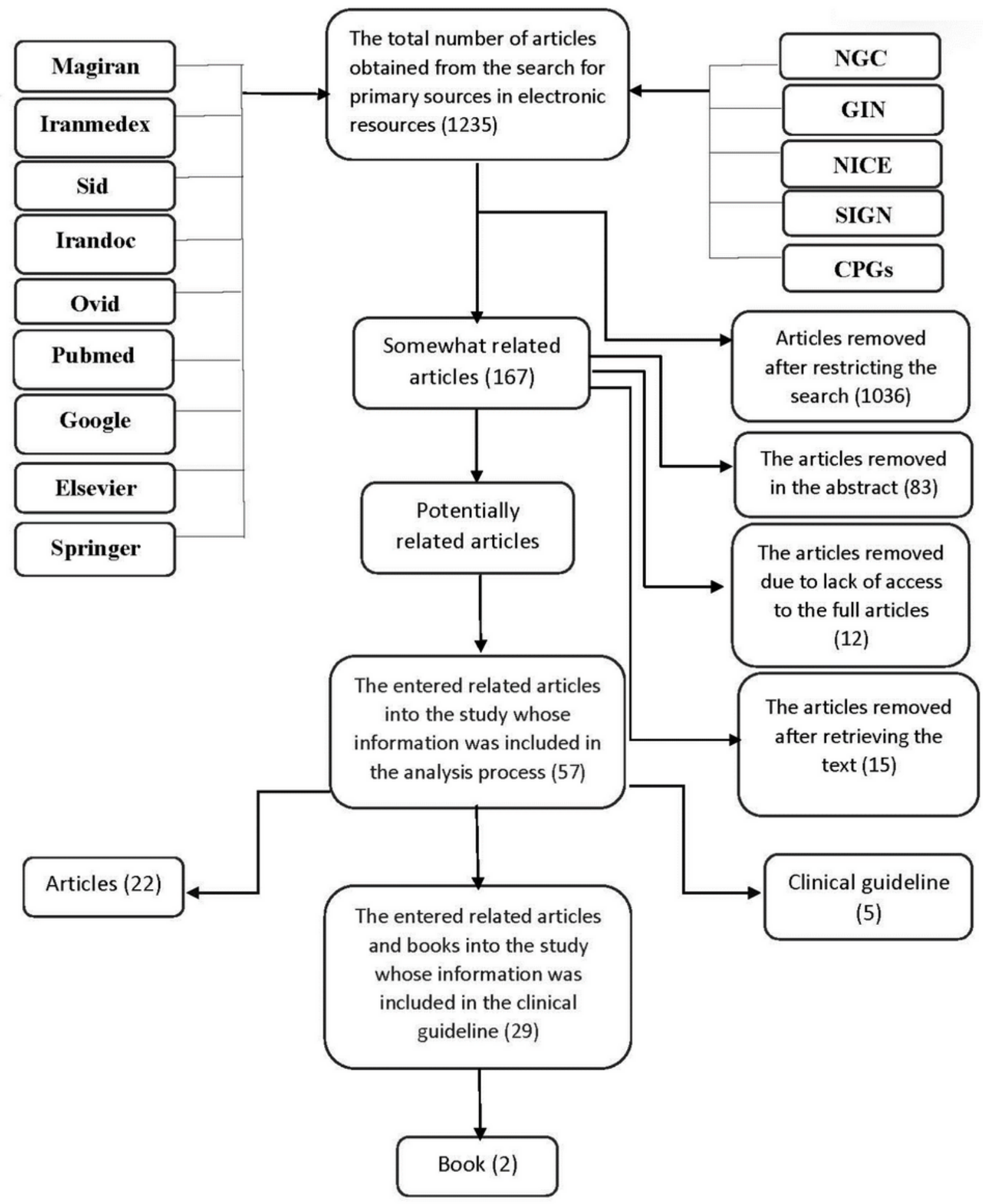

Figure 2

Flowchart of reviewing and searching the articles 